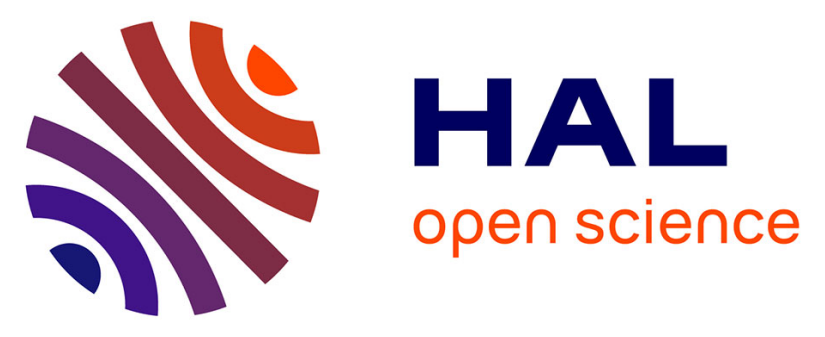

\title{
Construct Validity and Cross Validity of a Test Battery Modeling Autism Spectrum Disorder (ASD) in Mice
}

Pierre L. Roubertoux, Sylvie Tordjman, Xavier Caubit, Julie Di Cristopharo, Adeline Ghata, Laurent Fasano, Lydia Kerkerian-Le Goff, Paolo Gubellini, Michèle Carlier

\section{To cite this version:}

Pierre L. Roubertoux, Sylvie Tordjman, Xavier Caubit, Julie Di Cristopharo, Adeline Ghata, et al.. Construct Validity and Cross Validity of a Test Battery Modeling Autism Spectrum Disorder (ASD) in Mice. Behavior Genetics, 2020, 50 (26-40), 10.1007/s10519-019-09970-x . hal-02440792

\section{HAL Id: hal-02440792 \\ https://hal-amu.archives-ouvertes.fr/hal-02440792}

Submitted on 5 Mar 2020

HAL is a multi-disciplinary open access archive for the deposit and dissemination of scientific research documents, whether they are published or not. The documents may come from teaching and research institutions in France or abroad, or from public or private research centers.
L'archive ouverte pluridisciplinaire HAL, est destinée au dépôt et à la diffusion de documents scientifiques de niveau recherche, publiés ou non, émanant des établissements d'enseignement et de recherche français ou étrangers, des laboratoires publics ou privés. 
The original publication of this author version is available at www.springer.com: https://link.springer.com/article/10.1007\%2Fs10519-019-09970-x

\section{Construct validity and cross validity of a test battery modeling Autism Spectrum} Disorder (ASD) in mice

Pierre L. Roubertoux ${ }^{1}$, Sylvie Tordjman ${ }^{2,3}$, Xavier Caubit ${ }^{4}$, Julie di Cristopharo ${ }^{5}$ Adeline Ghata ${ }^{1}$, Laurent Fasano ${ }^{4}$, Lydia Kerkerian-Le Goff ${ }^{4}$, Paolo Gubellini ${ }^{4}$, Michèle Carlier $^{6,7}$.

\footnotetext{
${ }^{1}$ Aix Marseille Univ, INSERM, MMG, Marseille, France

${ }^{2}$ Paris Descartes Univ, CNRS, LPP, Paris, France

${ }^{3}$ Rennes 1 Univ, PHUPEA, Rennes, France

${ }^{4}$ Aix Marseille Univ, CNRS, IBDM, Marseille, France

${ }^{5}$ Aix-Marseille Univ, CNRS, EFS, Marseille, France

${ }^{6}$ Aix Marseille Univ, CNRS, LPC, Marseille, France
}

${ }^{7}$ Corresponding author: Michèle Carlier, Aix-Marseille Université CNRS UMR 7290 Psychologie cognitive, Fédération de Recherche 3C - Comportement Cerveau Cognition ; case D, Bât 9 - ST CHARLES, 3 Place Victor Hugo - 13003 Marseille, France

Tél: +33(0)4 13550988

e-mail : michele.carlier@univ-amu.fr

Running head: test battery for modeling Autism Spectrum Disorder in mice 


\begin{abstract}
Modeling in other organism species is one of the crucial stages in ascertaining the association between gene and psychiatric disorder. Testing Autism Spectrum Disorder (ASD) in mice is very popular but construct validity of the batteries is not available. We presented here the first factor analysis of a behavioral model of ASD-like in mice coupled with empirical validation. We defined fourteen measures aligning mouse-behavior measures with the criteria defined by DSM-5 for the diagnostic of ASD. Sixty-five mice belonging to a heterogeneous pool of genotypes were tested. Reliability coefficients vary from .68 to .81 . The factor analysis resulted in a three- factor solution in line with DSM criteria: social behavior, stereotypy and narrowness of the field of interest. The empirical validation with mice sharing a haplo-insufficiency of the zinc-finger transcription factor TSHZ3/Tshz3 associated with ASD shows the discriminant power of the highly loaded items.
\end{abstract}

Key words: Autism Spectrum Disorder, ASD, Factor analysis, mouse. 


\section{INTRODUCTION}

Autism spectrum disorder (ASD) is a neuro-developmental disorder involving social communication impairments and repetitive behaviors or interests with onset prior to age three years as defined by Diagnostic and statistical manual of mental disorders (DSM-5) (AAP 2013). These features are shared by a large set of rare genetic diseases (Tordjman et al. 2018). The number of genetic events associated with ASD increases with the development of high-throughput sequencing in psychiatry but most of the conclusions drawn from association studies are putative and need confirmation.

The persistent association of a gene with a disease in model species provides an additional argument to the association of a gene with a disease. This strategy requires an animal model that fulfills the validity criteria. We present here the first factorial validation and a cross validation of a test battery for modeling ASD in mice. The limitation of modeling in psychiatric disorders in rodents has been discussed elsewhere (Tordjman et al. 2007; Kas et al. 2014; Lévy and Roubertoux 2015; Kazdoba et al. 2016). Modeling a disease requires first a clinical reference before aligning animal and patient features (Lévy and Roubertoux 2015). Thirteen diagnostic tools are available including DSM criteria of ASD and diagnostic scales. They share common traits as shown by comparing the results of seven factor analyses (Shuster et al. 2014). We selected DSM-5 as a model that integrates recent findings of genetic psychiatry, eliminating references to intellectual deficiency and to language impairment that have low penetrance in ASD (Lai et al. 2014). DSM-5 is understood as being defined by two sets of criteria. The first includes social behavior impairment (SBI) items whereas the second includes items related to restricted and repetitive behaviors and interest (RRBI). The factor analyses extracted invariantly a SBI factor that DSM-5 refers to as "deficit in social communication and social interaction 
across multiple context". It can not be considered similar to either externalizing behavior or agonistic behavior that have low penetrance (present in $60 \%$ of the patients (Kanne and Mazurek 2011; Lundwall et al. 2017) and are not specific to ASD (Goldin et al. 2013; Tureck et al. 2013). The RRBI items are more heterogeneous than the SBI's suggesting a two-dimension category. Six of seven factor analyses support a two-factor model within the RRBI domain, and they extracted "repetitive sensory motor behavior" and "resistance to change" factors" (Bishop et al. 2006; Cuccaro et al. 2003; Mitaki et al. 2013; Richler et al. 2007; Raux et al. 2007; Szatmari et al. 2006). A principal component analysis with the Children's Yale-Brown Obsessive Compulsive Scale for children with autism spectrum disorder resulted in five independent factors. The Restricted interest and stereotypy factors independence persists (Scahill et al. 2014). A follow-up study demonstrated the stability of two sub-groups characterized by repetitive sensory-motor behaviors and restricted interests, in a population of ASD patients (Uljarevic et al. 2017). The repetitive sensory-motor behavior includes vocal and speech stereotypies, face (Tan et al. 1997), mouth (McDougle et al. 1995; Zuo et al. 2015), eyes (Mottron et al. 2007), neck (Mendez and Mirea 1998), as well as hand and finger stereotypies (MacDonald et al. 2007). Resistance to change includes items that cover circumscribed interests and that are defined as hyper-focused and abnormal in intensity (Grove et al. 2016; Smith et al. 2009; Turner-Brown et al. 2011).

We developed a mouse model of ASD hypothesizing a three-factor model with impairment of social behavior, narrowness of the fields of interest and stereotypy behavior. We aligned first the mouse behavioral observations with those provided by the clinical ones. For this purpose, three of the authors of the study (ST, MC and PLR) who have been trained in both the fields of psychiatry/psychology and biology defined 
behavioral measurements i) that were practical in mice and ii) that were congruent with the DSM-5 criteria for ASD diagnosis. We validated next the fourteen-task battery using a confirmatory factorial strategy. A cross validation of the measures was made with the Tshz $3^{\text {Lacz+ }}$ mouse model that shows several of the ASD-like behavioral features.

\section{MATERIAL AND METHODS}

\section{The mice}

Factorial validity

We examined 73 male mice between 81 and 97 days old. All were born in Marseille Medical Genetics facilities. They belong to 16 strains: $4 \mathrm{C} 57 \mathrm{BL} / 6 \mathrm{~N}, 4 \mathrm{CBA} /{ }^{\mathrm{MtH}}, \mathrm{CBA} /{ }^{\mathrm{MtN}}, 5$ Tshz3-pnCxKO and 5 control, 5 152F7x C57BL/6N.F1 and 5 control, 4 BTBR T+tf/J and 5 control, 5 129S2/SvPasOrIRj, 5 B6; 129S2-En2tm1Alj/J and 5 control, 5 NZB/BINJ, 4 Fmr1KO and 3 controls and 4 CD1x 129S2/SvPasOrIRj. Each mouse was subjected to the entire test battery.

\section{Cross-validation}

We tested blind naïve Tshz $3^{+/ L a c z}$ males and their wild type male littermates. Sample sizes ranged from 7 to 10 depending on the behavioral task - see the result section.

\section{Housing conditions}

Rearing conditions impact the phenotypes in rodents. Grouped mouse males frequently display agonistic behavior inducing irreversible hierarchical grouping (Ginsburg BE 1942; Maxson and Canastar 2003). Wild mice show autistic features when reared and maintained with conspecifics lacking neuroligin-3 (Kalbassi et al. 2017). Males from several of the strains listed show agonistic reactions or autistic-like features and cannot be reared together. The alternative social isolation is not conceivable because it 
generates undesirable behavioral and physiological long-term effects (Roubertoux 2015). We elected another solution. Each male to be tested was housed with a female to eliminate the biases resulting from isolation. We used transparent $35 \times 20 \times 18 \mathrm{~cm}$ cages with 1 l poplar woodchip bedding and with a cardboard dome house as enrichment. Food (Harlan Global Diet 2018) and water ad lib and a 12/12-hour light/dark period with lights turned on at $7 \mathrm{AM}$.

\section{Testing for sensorial impairments}

We examined vision, audition and olfaction in each mouse because results obtained in different tasks depend on the integrity of these functions. Each mouse was subjected to sensorial examinations before starting the battery.

Detecting visual impairment. We took the mouse by the tail between the thumb and the forefinger and lifted it. The tip of a pencil was approached to its eyes, without touching the vibrissae. The mouse raised the head, extended the forelimbs and grasped or tried to grasp the pencil when the visual function was undamaged. The scores were: raising the head (1), extending the forelimbs (2) and grasping or trying to grasp the pen (3).

Detecting auditory impairment. The Preyer response consists in pinna twitching and going flat backwards against the head as reaction to sound. The response was validated as an indicator of auditory acuity by measuring the associated averaged auditory potential (Francis 1979). We evaluated the responses to stimulations in the ultrasound bandwidth. The mice, placed in soundproof chamber, received sounds from two commercial dog whistles (10 cm from the ear). The first produced $50 \pm 0.08 \mathrm{kHz}$ and the second $35 \pm 0.10 \mathrm{kHz}$ sounds. The mouse received 5 stimulations from each whistle at 3 minutes intervals. The Preyer response was scored 1 for a partial response (ear startling) 
and 2 for a full response (pinna going flat backwards against the head).

Detecting the inability to identify social vs non-social odors. The tested mouse was alone in a ventilated room during the test. The olfactory habituation/dis-habituation test and scoring were performed according to previous protocol (Yang and Crawley 2009). We presented non-social odors (water, and synthetic sugar-free violet and vanilla aromas) and social odors (urine from $\mathrm{C} 57 \mathrm{BL} / 6 \mathrm{NCrl}$ and SWR male mice). An absence of olfactory impairment specific to social odors was confirmed when the mouse smells the tip of the tube containing social odors as longer as the non-social odors.

\section{Behavioral tests}

Sociability and interest in social novelty

Sociability is the number of interactions towards a conspecific and the interest in social novelty is the increased number of interactions towards a new conspecific. We measured the behaviors in a two-chamber condition as previously

Insert Figure 1 here

described (Figure 1) (Caubit et al. 2016; Roubertoux 2015) that followed the protocol by (Moy et al. 2009; Nadler et al. 2004). Stage 1: the mouse was put in zone 1 for habituation, the hole between 1 and 2 being closed $(5 \mathrm{~min})$. Stage 2: the two pencil boxes ( 3 and 4 ) were empty. The mouse was allowed to explore zones 1 and 2 . We counted the number of nose pokes on the two pencil boxes (10 min). Stage 3: a C57BL/6J (B6) male and a lure (a small oblong grey pebble) were placed into the pencil boxes 3 and 4 respectively. We counted the number of nose pokes on the two pencil boxes (10 $\mathrm{min}$ ). Stage 4: a SWR male was placed in 4 as a replacement of the lure. We counted the 
number of nose pokes on the two pencil-boxes (10 min). The positioning of B6 in stage 1 was randomized. The mice were video-recorded via a camera located $170 \mathrm{~cm}$ above the ground (Viewpoint-Behavior technologies).

Several modifications were made in comparison to the three-chamber test. The contacts (number of nose pokes) are a more direct measure than the time in the room containing the pencil-box. The location of the two pencil-boxes in a single zone rather than in three independent rooms reduces the covariance due to exploratory activity (Caubit et al. 2016). The measures are not independent a priori in the three-room version; indeed, when the tested male is in one room it is not in the others, because the total time in the rooms is a finite value. The conditions are not similar with the nose pokes because the number of nose pokes during a stage is not a priori finite. Three measures were considered. The number of nose pokes on the empty pencil-boxes during the second stage provided an estimate of the narrowness of the field of interest (labeled thereafter Exploration of new objects). The number of nose pokes on the pencil-box containing B6 minus the number of nose pokes on the empty pencil box during stage 3 was labeled Sociability. The number of nose pokes on the box containing SWR minus B6 during stage 3 was labeled Interest in social novelty.

Marble burying

The test quantifies repetitive and perseverating behavior (Njung'e and Handley 1991; Thomas et al. 2009). Mice were individually transferred in $40 \times 40 \times 18 \mathrm{~cm}$ cages with litter ( $5 \mathrm{~cm}$ thick) for $10 \mathrm{~min}$ habituation. At the end, the mouse was restricted to a corner of the cage with a mobile partition. Twenty marbles $(1 \mathrm{~cm}$ in diameter) were placed on top of the bedding. The partition being removed, the mouse was left alone for 30 
minutes. Completely covered, $2 / 3$ buried and $1 / 2$ buried marble were scored 3, 2 and 1 respectively (Thomas et al. 2009). The variable was labeled Marble-burying score.

\section{Litter box.}

Rodents display spontaneous digging and pushing behavior when they are placed in a new litter. Differences are observed in digging and pushing between strains or as consequences of mutations. A mouse was individually placed in a $40 \times 40 \times 18 \mathrm{~cm}$ cage with $5 \mathrm{~cm}$ thick new litter for $30 \mathrm{~min}$. We measured the time spent in digging and pushing that were grouped and labeled as Burrowing activity (s). We also measured time spent in selfgrooming (Self-grooming in the litter box (s)).

Hole-board test

Exposition of rodents to a hole-board condition gives rise to exploratory head dipping and stereotyped head dipping. Exploratory head dipping occurs when the mouse put its' head once into one hole of the board and stereotyped head dipping occurs when the head dips twice in the same hole within $2 \mathrm{~s}$ (Makanjuola et al. 1977). The apparatus consisted of a board $(40 \times 40 \mathrm{~cm})$ with 16 equidistant holes $(3.5 \mathrm{~cm}$ diameter) each equipped with photo-beams for detecting head dipping. The session lasted $10 \mathrm{~min}$ and was filmed. The score was the ratio number of stereotyped dips (counted)/ number of non-stereotyped dips (automatically recorded). The variable was labeled Proportion of stereotyped dips.

\section{Open field exploration test}

We selected the circular open field version rather than the square version that is more suitable for measuring anxiety because its' angles can be used as refuges. We placed always the mice at the same peripheral location $(100 \mathrm{~cm}$ diameter and $45 \mathrm{~cm}$ high walls). The ground was virtually divided in three concentric zones of equal surface. The 
distances walked and the times spent in the three zones were automatically measured via the Viewpoint-Behavior technologies system (http://www.viewpoint.fr/news.php). The observation lasted $20 \mathrm{~min}$. Three variables measured the narrowness of the field of interest. 1) The distance walked in the peripheral zone / total distance walked (labeled Peripheral zone proportion). 2) The number of zone crossings expressed as the sum of crossings / total distance walked (labeled Zone crossing proportion). 3) The distance walked in exploring the central zone was expressed as a proportion of the total distance walked in the open field (Distance in the central area proportion). We counted also the number of grooming episodes during the open field test (Number of self-grooming episodes), the Number of rearing, the number of leaning on the wall (Number of leanings) and the Number of jumping.

Anxiety-like measure. The prevalence of anxiety reaches 34 to 46\% (Lai et al, 2014, annex table 2) but it reached a proportion that was not considered sufficient to be included among the DSM-5 core features. The elevated plus maze provides a measure of anxiety-like behavior based on the avoidance of an anxiogenic condition that we measured to clarify the possible contribution of anxiety to the selected variables. We used a plus-shaped device with two open arms and two closed arms, elevated $80 \mathrm{~cm}$ from the floor. Each mouse was placed in the central area of the maze $(6 \times 6 \mathrm{~cm})$ with its head towards the enclosed arm, and allowed to move freely for $15 \mathrm{~min}$. The distance walked in the opened arms and the number of crossings of the open-closed common zone was measured by a video tracking system (http://www.viewpoint.fr/news.php). We counterbalanced the distance walked in the open arms by the crossing distance (Relative distance in open arms). 
The whole battery of tests, including the sensorial screening and the retest sessions, lasted $230 \mathrm{~min}$. We avoided tiredness by subjecting daily each mouse to a single long test or two shorter tests. Total duration per day does not exceed 55 min. The order of testing was randomized. We cleaned the apparatus with house soap after each examination.

\section{Statistical analysis}

We used SPSS version 19 for all the statistics. We transformed before subsequent analyses the raw data ( Log10 + constant) to obtain distributions that were compatible with normality (Kolmogorov-Smirnov and Shapiro-Wilk tests) when necessary.

Reliability of the measures

We computed internal consistency (split half reliability, Spearman-Brown formula) for Exploration of new object, Sociability, Interest in social novelty ( 5 first min vs 5 last min) and for the measures performed in the open field (10 first min vs 10 last min). Litter box, Marble-burying and Hole board were applied twice (a week later) and we calculated the Cronbach test-retest coefficients.

Factor analysis

The three-factor structure hypothesis based on DSM- 5 criteria leads to choose a confirmatory approach. We selected 1) the maximum likelihood extraction method with a $\chi^{2}$ of goodness-of-fit (Cangur et al. 2016; Ercan et al. 2015) and 2) the Varimax rotation after Kaiser normalization. The loading of a variable being defined as its correlation with the factor, we selected a threshold corresponding to $\mathrm{N}=65$ mice. We took a 0.01 value corresponding to $r=0.31$ as the limit of significance.

The diversity of the measures used for stereotypy required a factor analysis focused on selected measures: number of rearing, number of jumping, number of leaning and 
number of self-grooming episodes in the open field, burrowing activity, marble burying score, proportion of stereotyped dips in hole-board, and self-grooming in the litter box. This selective factor analysis was conducted as the previous one.

Correlations with anxiety-like measures

We investigated a possible impact of anxiety on the behavioral measures by calculating the correlations of the Relative distance in open arms with each behavioral measure and with the latent scores (factor scores).

Cross validation with Tshz $3^{+/ L a c z}$

We used mice from our Tshz $3^{\text {Lacz+ }}$ colony, but the individuals were different from those observed in a former study (Caubit et al. 2016) and from those used in the factor analysis. We used non-parametric statistics after considering the shape of the distributions and the sample size. The effect size statistics are preferred to the probability of rejecting the null hypothesis (Wasserstein and Lazar, 2016). The pathology appears when the difference with the typical group is large. We calculated the effect size after transforming $U$ values into $z$ scores and we expressed the size as the percentage of the total variance of the dependent variable associated with differences between the two groups $\left(\eta^{2}\right)$. We considered $\eta^{2}=.14$ (or Cohen's $d=.80$ ) as a large effect (Cohen, 1988) but we need also larger sizes of the effect because we model pathological features. We selected $\eta^{2}=.30$ (Cohen's $d==1.33$ ) as mild impairment, and $\eta^{2}=.50($ Cohen's $d=2)$ as impairment (Caubit et al., 2016; Roubertoux et al., 2017; Chabbert et al. 2019).

\section{RESULTS}

Sensorial screening 
We eliminated two mice for blindness, one for anosmia and one for deafness. Sixtynine mice were tested in total. Due to incidents four additional mice were eliminated leaving 65 mice in the final sample. Due to missing data in only one variable for some mice we choose to keep "pairwise option" in subsequent statistical analyses ( $\mathrm{N}$ varies between 63 to 65$)$.

Normality of the distributions

Six out of the fourteen variables required transformation, as they did not fulfill the Kolmogorov- Smirnov and Shapiro-Wilk criteria for normality (supplemental table 1). We failed to find a suitable transformation for Number of rearing and Number of jumping but replacing $r$ by the non-parametric rho (not shown) resulted in coefficients that were closed to those reported in table 1.

Reliability of the measures

Twelve out of the fourteen coefficients exceeded 0.75 , which is considered as a high reliability. The two measures of grooming were slightly less reliable (Table 1).

Insert Table 1 here

\section{Correlation table}

The Pearson correlations are shown in Table 2. The shape of the distribution did not impact the correlation values for Number of rearing and Number of jumping, which did not fulfill the criteria for normality. Previous analyses shown that 1) the sizes of the correlations were not modified when we substituted Spearman rho for Pearson $r$ (not shown), 2) that the correlations between the variables were stable from 45 to 60 
observations indicating that the sample size was sufficient. Two criteria supported the appropriateness of the sample for a factor analysis in a sub-sample of the variables, including the stereotypy measures only, as well as in the whole sample of the variables. The Kaiser-Meyer-Olkin (Cerny and Kaiser 1977) measure of sampling adequacy was 0.7 and the $\chi^{2}$ of the Bartlett's test of sphericity (Tobias and Carlson 1969) of the same sample reached significance $\left(\chi^{2}=112.19 ; p=4.96^{\mathrm{E}-25} ; \mathrm{df} 28\right)$ for the partial analysis with stereotypy. For the whole sample of variables, the measure of sampling adequacy was 0. 6 and the $\chi^{2}$ of the Bartlett's test of sphericity reached significance $\left(\chi^{2}=439.71 ; p=3.0^{E-}\right.$ $\left.{ }^{19} ; \mathrm{df}=91\right)$.

Insert Table 2 here

Factor analysis

The $\chi^{2}$ of goodness-of-fit indicates that the two-factor solution was the best for the partial analysis with stereotypy (Table 3) whereas the five-factor solution was the best for the global analysis of the fourteen measures (Table 3). The two conclusions correspond with those drawn from the decrease of the eigenvalues (Kaiser' criterion).

Insert Table 3 here

Supplemental table 2 shows the loadings of the 14 variables after extraction of 5 factors (before rotations) and tables 4 and 5 show the varimax rotation matrix solution for the eight measures of stereotypy and for the whole analysis, respectively. 


\section{Cross validation}

We compared here naïve $T s h z 3^{+/ L a c z}$ haplo-insufficient mice and their wild-type (wt) littermate (Figure 2). Significant differences (one tailed) were found for eleven variables: Distance walked in the peripheral zone proportion (Figure $2 \mathrm{~A}, \mathrm{U}=0 ; \mathrm{p}=0.00002 ; \eta^{2}=0.71$; $\mathrm{N}=9$ in each group); Zone crossing proportion (Figure $2 \mathrm{~B}, \mathrm{U}=0, \mathrm{p}=0.00007 ; \eta^{2}=0.71, \mathrm{~N}=$ 8 in each group); Distance in the central area proportion (Figure $2 C, U=14, p=0.03 ; \eta^{2}=$ $0.22 ; \mathrm{N}=9$ in each group); Number of rearing (Figure $2 \mathrm{D}, \mathrm{U}=12.5, \mathrm{p}=0.02 ; \eta^{2}=0.26 ; \mathrm{N}=8$ in each group); Burrowing activity (Figure $2 E, U=0, p=0.0002 ; \eta^{2}=0.70 ; N=7$ in each group); Number of jumping (Figure $2 \mathrm{~N}, \mathrm{U}=23, \mathrm{p}=0.01 ; \eta^{2}=0.32 ; \mathrm{wt} \mathrm{N}=9$ and Tshz3/ $\left.\right|^{\text {Lacz+ }}=$ 10); Marble-burying score (Figure $2 \mathrm{G}, \mathrm{p}=0.02 ; \eta^{2}=0.26 ; \mathrm{N}=8$ in each group); Sociability (Figure $2 \mathrm{H}, \mathrm{U}=0, \mathrm{p}=0.00002 ; \eta^{2}=0.56 ; \mathrm{N}=9$ wild type and $10 \mathrm{KO}$ ); Interest in social novelty (Figure 2l, $\mathrm{U}=5, \mathrm{p}=0.0003 ; \eta^{2}=0.60 ; \mathrm{N}=9$ wild type and $10 \mathrm{KO}$ ); Proportion of stereotyped dips (Figure J, $U=0, p=0.00007 ; \eta^{2}=0.71 ; \mathrm{N}=9$ in each group). The other variables (Exploration of new object, Number of leanings) and the two measures of grooming (Self-grooming in the litter box, and Number of self-grooming episodes in the open field) do not reach significance ( $0.29,0.42,0.16$ and 0.23 respectively) with very low effect sizes (between o to 0.07).

Insert Figure 2

Correlations with anxiety-like measures 
We calculated the correlation ( $r$ ) between anxiety-like measure and i) the fourteen variables and ii) the factor scores. The correlation values were reported in the last column of Table 2. Two significant values were obtained with the scores of factors 3 and $4(r=$ $0.285 ; p<.05 ; \eta^{2}=0.080$ and $r=-0.293 ; p<.05 ; \eta^{2}=0.086$, respectively).

\section{DISCUSSION}

Matching in mice behavioral measures with clinical features

We defined fourteen measures aligning mouse-behavior measures with the criteria defined by DSM-5 for the diagnostic of ASD. Social behavior impairment defined by DSM- 5 includes neither tantrums nor externalizing behavior or agonistic behavior as mentioned above. It should be therefore meaningless to consider agonistic behavior and to measure the liability to induce attack in dyadic encounters for modeling ASD. Including vocalization (number, frequency of sounds and ultrasounds) into the communication processes (Irie et al. 2012; Silverman et al. 2010) may be premature. Little is known on the physiology of ultrasound production (Arriaga and Jarvis 2013; Mahrt et al. 2016) and their function in communication is still disputed (Portfors and Perkel 2014). Their contribution to pupretrieving behavior has been questioned (Cohen-Salmon et al. 1985; Roubertoux et al. 1996). We selected thereby sociability and preference for social novelty measures that tally with DSM-5 items. The two measures are generally significantly correlated, and this is the case in our sample $(r=0.30)$ but they may be occasionally dissociated (Pearson et al. 2010; Sorensen et al. 2015; Yadav et al. 2012).

Repetition, invariance and idiosyncrasies characterize stereotypy. We selected eight measures that fulfill the criteria and that are widely used in modeling ASD in mice. We extracted the stereotypy measures from four different experimental conditions: 1) a long time spent in digging and pushing (burrowing activity) indicates a repetitive activity; 2) a 
high marble-burying score detects a repetitive behavior (Thomas et al. 2009). Ten papers showed that mice in models of ASD buried more the marbles indicating its relevance for ASD modeling. 3) The open field condition offered three measures of repetitive behavior: leaning, jumping, and self-grooming. Leaning, jumping, and grooming differentiate ASDlike mutant mice (Rizzo 2016; Silverman et al. 2012). Self-grooming behavior has been considered as an indicator of anxiety in mice but neither grooming nor the other measures of stereotypy were correlated with anxiety-like behavior (except number of leaning in which it contributes only to $6.8 \%$ of the variance, see Table 2 ). Its stereotypical facets were demonstrated (Berridge et al. 2005) and several studies show that it can differentiate ASDlike mice from controls. 4) Repeated head dipping observed during the hole-board condition differentiates mice models of ASD from their respective controls (Caubit et al. 2016; Irie et al. 2012).

All the stereotypy measures selected implicate striatal structures (Graybiel and Rauch 2000; Gillan et al. 2011; Murray et al. 2015) and the glutamatergic system (Horder et al. 2013) burrowing and marble burying (Hashemi et al. 2007; Welch et al. 2007), leaning (Jousselin-Hosaja et al. 2003), jumping (Presti et al. 2004) stereotypical head dipping in mice (Irie et al. 2012) and self-grooming (Yu et al. 2018), but several groups have however questioned the uniqueness of the stereotypy concept (Bodfish et al. 2000; Eilam et al. 2006; Meiselas et al. 1989; Muthugovindan and Singer 2009; Peter et al. 2017). Accordingly, a partial analysis with the stereotypy measures (table 4) shows here that they belong to two domains. Five measures defined the first factor as a stereotypy factor with the highest loadings for Burrowing activity and Marble burying score. The second factor may be analyzed as a repetitive compulsive activity factor considering (Berridge et al. 2005) for Self-grooming in the litter box and (Makanjuola et al. 1977) for Proportion of 
stereotyped dips.

We used here the personal-space regulation paradigm for modeling the narrowness of the field of interest. Persons with ASD use non-typically their personal space. They keep a large distance with a partner (Gessaroli et al. 2013) and they prefer also small closed spaces or well-known spaces even when they are alone (Kawa and Pisula 2010). We measured the distance walked on the round peripheral strip, which is a circumscribed part of the open field. This measure is different from the thigmotaxis (from Greek "thigma" and "taxi” meaning “touch" and "movement" respectively) observed in a squared open-field where the time in corners serving as a refuge is indicative of anxiety. In the circular openfield it is analyzed as a cognitive strategy and particularly as a spatial novelty detection process (Khanegheini et al. 2015). A long time or a long distance walked in the peripheral strip indicates a circumscribed exploration of the arena by the mouse that neglects the non-peripheral strips. The circular open field set up provides a second estimate of the narrowness of the field of interest. The three strips (peripheral, median and central) do not have the same attractive value. There is a negative gradient of interest from the peripheral to the central strip. The narrowness of the field of interest can be inferred from a scarce zone-crossing behavior. A third measure is the distance walked in the central zone, which is the least attractive of the open field. The measures made during the squared open field condition have been considered as measures of anxiety, but we did not find significant correlations with the measures of the field of interest in the circular open field condition and the anxiety-like score (Table 2).

Fourteen measures resulted from our attempts to align mouse behavioral traits with the clinical criteria proposed by DSM-5. Face validation defined three groups of variables 
resulting from the separation between restricted field of interest and stereotypic activity to which social behavior is added.

\section{Factorial validation}

Our purpose was to attempt a factorial validation of the three-factor structure of the battery. We confirmed first the appropriateness of a factor analysis. The latent variables of the 14-variable correlation matrix (table 2) contribute to the variance of the measures (Cerny and Kaiser 1977). Moreover, the deviation of the correlation matrix from an identity matrix, indicating no relation between the variables of the matrix (Bartlett's test), differed significantly from zero. Taken together, the results show that the matrix was appropriate for a factor analysis. We extracted the factors and the $\chi^{2}$ of goodness of fit indicated that no significant additional covariance remains after the fifth factor extraction (table 3). Three significant loadings are generally required to define a factor. The fifth factor was not analyzable because of this. The fourth factor opposing selfexploration and the exploration of an object defines a mouse behavior specific axis.

The three first factors are related to the autistic core features. The first is a narrowness of the field of interest factor. It is defined by a high loading of peripheral zone exploration that corresponds to a restricted field of interest on one extremity of the axis whereas the three items indicating larger fields of interest have high or significant loadings on the opposite end of the same axis. These items are the high number of zones crossed, the exploration of the less attractive zone, and rearing that can be considered as a seeking stimulation activity (Lever et al. 2006).

The second factor loads five variables that were defined as repetitive behavior. They belong to three different experimental tasks: spontaneous activity in the litter box, open field and marble burying. The location of number of grooming-self episodes on the 
opposite part of the second axis was expected. Grooming is a repetitive activity that implies a sit position whereas the others imply movements. Factor 2 can be analyzed as a liability to stereotypy factor opposing stereotypy expressed during movements and selfdirected activity. A contribution of anxiety to the items seems to be excluded from the two first factors, as we found no correlation of anxiety-like measures with the items loaded in the first or in the second factor (table 2). The scores of the factors 1 and 2 did not reach significance indicating that neither individually nor in groups the items were anxiety-like dependent. The very low correlation between the factor scores of these two first factors (-0.074) confirmed that narrowness of the field of interest and liability to repetitive behavior provide independent criteria in ASD patients (Boomsma et al. 2008; Frazier et al. 2008; Georgiades et al. 2007; van Lang et al. 2006; Mandy and Skuse 2008) and in mouse models.

Congruent loadings of sociability and preference for social novelty characterize the third factor as a social-relationships impairment factor. They have similar loadings confirming their association although they are sometimes non-associated (Pearson et al. 2010; Sorensen et al. 2015; Yadav et al. 2012). We suggest considering them as two measures of the same trait rather than the measures of two different traits. The list of protocols investigating social behavior is short and it should be extended. The protocols measuring empathy for instance may offer an outcome (Jeon et al. 2010; Warrier et al. 2018). They are based on observational learning and consequently knowledge of the contribution of cognitive abilities to empathy coefficients should be clarified. The proportion of stereotyped dips in the hole-board was loaded on the second factor of the partial analysis with measures of stereotypy and it may be analyzed as a measure of compulsive behavior (table 4). Its location at the opposite end of the items measuring 
social behavior fits with clinical reports of a high prevalence of social behavior impairment in patients with obsessive-compulsive disorders (Ivarsson and Valderhaug 2006; Ivarsson and Winge-Westholm 2004) and with pharmacology showing that inducing compulsive behavior in mice impairs sociability (Wolmarans et al. 2017).

The factorial validation of fourteen measures in mice results in a three-factor solution that is in line with the one obtained with DSM criteria. A social behavior factor is defined but also a stereotypy factor and a narrowness of the field of interest factor.

\section{Cross validation}

We used the 14 items to study the haplo-insufficiency of the zinc-finger transcription factor TSHZ3/Tshz3 (Caubit et al. 2005) that is known for causing ASD in patients as well as in mice models (Caubit et al. 2016). Among the fourteen variables tested here, seven had been also tested in the former paper and all the results were replicated in the new set of $\mathrm{Tshz3}^{+/ \mathrm{Lacz}}$ mice and wt mice (see Figure $2 \mathrm{~A}, \mathrm{~B}, \mathrm{C}, \mathrm{G}, \mathrm{H}, \mathrm{I}$, and $\mathrm{J}$ ). The four measures defining " the narrowness of the field of interest" factor discriminate the Tshz $3^{+/ L a c z}$ from the wt. The two firsts (Distance walked in the peripheral zone and Zone crossing proportion) show impaired performance. Four of the measures that define the stereotypy factor discriminate $\mathrm{Tshz}^{+/ \text {Lacz }}$ from the wt. Burrowing activity, Proportion of stereotyped dips, Number of jumping and Marble burying score; the three firsts show impairment. The two measures that define social behavior are also impaired.

\section{General conclusion}

Although very popular, the mouse modeling of ASD has never been subjected to a factor analysis. We present here the first factorial validation of a test battery for modeling ASD in the Mouse. In a deliberate manner, we limited ourselves to the behavioral domain 
because ASD is defined in terms of behavior since the first tools for diagnosis were developed (Roubertoux and Tordjman 2015). The factorial validation was part of a larger process including cross validation. We confirmed a three-factor model with independent dimensions: restricted field of interest, repetitive behavior and social impairment, on which further neurophysiological studies should be based. We suggest that revisiting the stereotypy-compulsive category at the clinical level and at the neurophysiological level should result in a better understanding of ASD. The results can be read also as a caveat. A trait has rarely a general meaning; it varies according to the condition in which it is observed. Self-grooming is exemplary from this point of view. It does not belong to the same factor when it is recorded in the open field or in the litter box. A second benefit is the possibility to reduce time-consuming testing by selecting for one factor the item that shows the highest loading. We select the distance walked in peripheral zone, burrowing activity (or marble burying for a more rapid examination) and sociability for each of the three factors.

\section{Acknowledgements}

All the authors reviewed the manuscript for intellectual content and approved submission.

\section{Funding}

Aix Marseille University, Inserm and CNRS funded the study.

\section{Compliance with ethical standards}

All animal experiments were in accordance with the local and national

Ethical Committees procedures and in agreement with the recommendations of the EEC (86/609/EEC). 


\section{Conflict of interest}

Pierre L. Roubertoux, Sylvie Tordjman, Xavier Caubit, Julie di Cristopharo, Adeline Ghata, Laurent Fasano, Lydia Kerkerian-Le Goff, Paolo Gubellini, and Michèle Carlier declare that they have no conflict of interest.

\section{References}

APA (2013) Diagnostic and statistical manual of mental disorders DSM-5. American psychiatric association, Washington

Arriaga G, Jarvis ED (2013) Mouse vocal communication system: are ultrasounds learned or innate? Brain and language 124(1):96-116

Berridge KC, Aldridge JW, Houchard KR, Zhuang X (2005) Sequential super-stereotypy of an instinctive fixed action pattern in hyper-dopaminergic mutant mice: a model of obsessive compulsive disorder and Tourette's. BMC biology 34

Bishop SL, Richler J, Lord C (2006) Association between restricted and repetitive behaviors and nonverbal IQ in children with autism spectrum disorders. Child neuropsychology : a journal on normal and abnormal development in childhood and adolescence 12(4-5):247-267

Bodfish JW, Symons FJ, Parker DE, Lewis MH (2000) Varieties of repetitive behavior in autism: comparisons to mental retardation. Journal of autism and developmental disorders $30(3): 237-243$ 
Boomsma A, Van Lang ND, De Jonge MV, De Bildt AA, Van Engeland H, Minderaa RB (2008) A new symptom model for autism cross-validated in an independent sample. Journal of child psychology and psychiatry, and allied disciplines 49(8):809-816 Cangur S, Ankarali H, Pasin O (2016) Comparing Performances of Multiple Comparison Methods in Commonly Used 2 x C Contingency Tables. Interdisciplinary sciences, computational life sciences 8(4):337-345

Caubit X, Gubellini P, Andrieux J, Roubertoux PL, Metwaly M, Jacq B, Fatmi A, Had-Aissouni L, Kwan KY, Salin P, Carlier M, Lieden A, Rudd E, Shinawi M, Vincent-Delorme C, Cuisset JM, Lemaitre MP, Abderrehamane F, Duban B, Lemaitre JF, Woolf AS, Bockenhauer D, Severac D, Dubois E, Zhu Y, Sestan N, Garratt AN, Goff LK, Fasano L (2016) TSHZ3 deletion causes an autism syndrome and defects in cortical projection neurons. Nature genetics 48(11):1359-1369

Caubit X, Tiveron MC, Cremer H, Fasano L (2005) Expression patterns of the three Teashirtrelated genes define specific boundaries in the developing and postnatal mouse forebrain. The Journal of comparative neurology 486(1):76-88

Cerny BA, Kaiser HF (1977) A Study Of A Measure Of Sampling Adequacy For FactorAnalytic Correlation Matrices. Multivariate behavioral research 12(1):43-47

Chabbert D., Caubit X., Roubertoux P.L., Carlier M., Habermann B., Jacq B., Salin P, Metwaly M., Frahm,C., Fatmi,A., Garratt A.N., Severac D., Dubois E., Kerkerian-Le Goff L., Fasano L., Gubellini P. (2019) Postnatal Tshz3 Deletion Drives Altered Corticostriatal Function and Autism Spectrum Disorder-like Behavior. Biological Psychiatry 86:274285

Cohen J (1988) Statistical power analysis for the behavioral sciences ( $2^{\text {nd }}$ Ed). Lawrence Earlbaum Associates., Hillsdale, NJ 
Cohen-Salmon C, Carlier M, Roubertoux P, Jouhaneau J, Semal C, Paillette M (1985)

Differences in patterns of pup care in mice. V--Pup ultrasonic emissions and pup care behavior. Physiology \& behavior 35(2):167-174

Cuccaro ML, Shao Y, Grubber J, Slifer M, Wolpert CM, Donnelly SL, Abramson RK, Ravan SA, Wright HH, DeLong GR, Pericak-Vance MA (2003) Factor analysis of restricted and repetitive behaviors in autism using the Autism Diagnostic Interview-R. Child psychiatry and human development 34(1):3-17

Eilam D, Zor R, Szechtman H, Hermesh H (2006) Rituals, stereotypy and compulsive behavior in animals and humans. Neuroscience and biobehavioral reviews $30(4): 456-471$

Ercan I, Sigirli D, Ozkaya G (2015) Examining the variations in the results of the Hotelling $T(2)$ test in case of changing baseline landmarks in the Bookstein coordinates. Interdisciplinary sciences, computational life sciences

Francis RL (1979) The Preyer reflex audiogram of several rodents, and its relation to the "absolute" audiogram in the rat. The Journal of auditory research 19(3):217-233

Frazier TW, Youngstrom EA, Kubu CS, Sinclair L, Rezai A (2008) Exploratory and confirmatory factor analysis of the autism diagnostic interview-revised. Journal of autism and developmental disorders 38(3):474-480

Georgiades S, Szatmari P, Zwaigenbaum L, Duku E, Bryson S, Roberts W, Goldberg J, Mahoney W (2007) Structure of the autism symptom phenotype: A proposed multidimensional model. Journal of the American Academy of Child and Adolescent Psychiatry 46(2):188-196

Gessaroli E, Santelli E, di Pellegrino G, Frassinetti F (2013) Personal space regulation in childhood autism spectrum disorders. PloS one 8(9):e74959 
Gillan CM, Papmeyer M, Morein-Zamir S, Sahakian BJ, Fineberg NA, Robbins TW, de Wit S (2011) Disruption in the balance between goal-directed behavior and habit learning in obsessive-compulsive disorder. The American journal of psychiatry 168(7):718-726

Ginsburg BE, Allee WC (1942) Some effects on conditioning on social dominance and subordination in inbred strains of mice. Physiology and Zoology 15485-506

Goldin RL, Matson JL, Tureck K, Cervantes PE, Jang J (2013) A comparison of tantrum behavior profiles in children with ASD, ADHD and comorbid ASD and ADHD. Research in developmental disabilities 34(9):2669-2675

Graybiel AM, Rauch SL (2000) Toward a neurobiology of obsessive-compulsive disorder. Neuron 28(2):343-347

Grove R, Roth I, Hoekstra RA (2016) The motivation for special interests in individuals with autism and controls: Development and validation of the special interest motivation scale. Autism research : official journal of the International Society for Autism Research 9(6):677-688

Hashemi E, Sahbaie P, Davies MF, Clark JD, DeLorey TM (2007) Gabrb3 gene deficient mice exhibit increased risk assessment behavior, hypotonia and expansion of the plexus of locus coeruleus dendrites. Brain research 1129(1):191-199

Horder J, Lavender T, Mendez MA, O'Gorman R, Daly E, Craig MC, Lythgoe DJ, Barker GJ, Murphy DG (2013) Reduced subcortical glutamate/glutamine in adults with autism spectrum disorders: a [(1)H]MRS study. Translational psychiatry $3 e 279$

Irie F, Badie-Mahdavi H, Yamaguchi Y (2012) Autism-like socio-communicative deficits and stereotypies in mice lacking heparan sulfate. Proceedings of the National Academy of Sciences of the United States of America 109(13):5052-5056 
Ivarsson T, Valderhaug R (2006) Symptom patterns in children and adolescents with obsessive-compulsive disorder (OCD). Behaviour research and therapy 44(8):11051116

Ivarsson T, Winge-Westholm C (2004) Temperamental factors in children and adolescents with obsessive-compulsive disorder (OCD) and in normal controls. European child \& adolescent psychiatry 13(6):365-372

Jeon D, Kim S, Chetana M, Jo D, Ruley HE, Lin SY, Rabah D, Kinet JP, Shin HS (2010) Observational fear learning involves affective pain system and Cav1.2 Ca2+ channels in ACC. Nature neuroscience 13(4):482-488

Jousselin-Hosaja M, Tobin C, Venault P, Joubert C, Chapouthier G (2003) Effects of adrenal medulla graft on recovery of GABAergic and dopaminergic neuron deficits in mice: behavioural, pharmacological and immunohistochemical study. Behavioural brain research 140(1-2):185-193

Kalbassi S, Bachmann SO, Cross E, Roberton VH, Baudouin SJ (2017) Male and Female Mice Lacking Neuroligin-3 Modify the Behavior of Their Wild-Type Littermates. eNeuro 4(4):

Kanne SM, Mazurek MO (2011) Aggression in children and adolescents with ASD: prevalence and risk factors. Journal of autism and developmental disorders $41(7): 926-937$

Kas, MJ, Glennon, JC, Buitelaar J, Ey E, Biemans B, Crawley J, Ring RH, Lajonchere, Esclassan F, Talpos J, Noldus LPJJ, Burbach JPH, Steckler T (2014). Assessing behavioural and cognitive domains of autism spectrum disorders in rodents: current status and future perspectives. Psychopharmacology $231: 1125-1146$ 
Kawa R, Pisula E (2010) Locomotor activity, object exploration and space preference in children with autism and Down syndrome. Acta neurobiologiae experimentalis $70(2): 131-140$

Kazdoba TM, Leach PT, Yang M, Silverman JL, Solomon M, Crawley JN (2015). Translational Mouse Models of Autism: Advancing Toward Pharmacological Therapeutics, in: Robbins, T.W., Sahakian, B.J. (Eds.), Translational Neuropsychopharmacology. Springer International Publishing p 1-52

Khanegheini A, Nasehi M, Zarrindast MR (2015) The modulatory effect of CA1 GABAb receptors on ketamine-induced spatial and non-spatial novelty detection deficits with respect to $\mathrm{Ca}(2+)$. Neuroscience $305157-168$

Lai MC, Lombardo MV, Baron-Cohen S (2014) Autism. Lancet 383(9920):896-910

Lever C, Burton S, O'Keefe J (2006) Rearing on hind legs, environmental novelty, and the hippocampal formation. Reviews in the neurosciences 17(1-2):111-133

Lévy N, Roubertoux PL (2015) Organism model: choosing the good model. In: Roubertoux P (ed) Organism model of autism spectrum disorders. Springer, New York, pp 3-28 Lundwall RA, Stephenson KG, Neeley-Tass ES, Cox JC, South M, Bigler ED, Anderberg E, Prigge MD, Hansen BD, Lainhart JE, Kellems RO, Petrie JA, Gabrielsen TP (2017) Relationship between brain stem volume and aggression in children diagnosed with autism spectrum disorder. Research in autism spectrum disorders 3444-51

MacDonald R, Green G, Mansfield R, Geckeler A, Gardenier N, Anderson J, Holcomb W, Sanchez J (2007) Stereotypy in young children with autism and typically developing children. Research in developmental disabilities 28(3):266-277 
Mahrt E, Agarwal A, Perkel D, Portfors C, Elemans CP (2016) Mice produce ultrasonic vocalizations by intra-laryngeal planar impinging jets. Current biology : CB 26(19):R880-R881

Makanjuola RO, Hill G, Dow RC, Campbell G, Ashcroft GW (1977) The effects of psychotropic drugs on exploratory and stereotyped behaviour of rats studied on a hole-board. Psychopharmacology 55(1):67-74

Mandy WP, Skuse DH (2008) Research review: What is the association between the socialcommunication element of autism and repetitive interests, behaviours and activities? Journal of child psychology and psychiatry, and allied disciplines 49(8):795-808

Maxson SC, Canastar A (2003) Conceptual and methodological issues in the genetics of mouse agonistic behavior. Hormones and behavior 44(3):258-262

McDougle CJ, Kresch LE, Goodman WK, Naylor ST, Volkmar FR, Cohen DJ, Price LH (1995) A case-controlled study of repetitive thoughts and behavior in adults with autistic disorder and obsessive-compulsive disorder. The American journal of psychiatry 152(5):772-777

Meiselas KD, Spencer EK, Oberfield R, Peselow ED, Angrist B, Campbell M (1989) Differentiation of stereotypies from neuroleptic-related dyskinesias in autistic children. Journal of clinical psychopharmacology 9(3):207-209

Mendez MF, Mirea A (1998) Adult head-banging and stereotypic movement disorders. Movement disorders : official journal of the Movement Disorder Society 13(5):825828 
Mitaki S, Isomura M, Maniwa K, Yamasaki M, Nagai A, Nabika T, Yamaguchi S (2013) Impact of five SNPs in dopamine-related genes on executive function. Acta neurologica Scandinavica 127(1):70-76

Mottron L, Mineau S, Martel G, Bernier CS, Berthiaume C, Dawson M, Lemay M, Palardy S, Charman T, Faubert J (2007) Lateral glances toward moving stimuli among young children with autism: Early regulation of locally oriented perception? Development and psychopathology 19(1):23-36

Moy SS, Nadler JJ, Young NB, Nonneman RJ, Grossman AW, Murphy DL, D'Ercole AJ, Crawley JN, Magnuson TR, Lauder JM (2009) Social approach in genetically engineered mouse lines relevant to autism. Genes, brain, and behavior 8(2):129-142

Murray RC, Logan MC, Horner KA (2015) Striatal patch compartment lesions reduce stereotypy following repeated cocaine administration. Brain research 1618286-298

Muthugovindan D, Singer H (2009) Motor stereotypy disorders. Current opinion in neurology 22(2):131-136

Nadler JJ, Moy SS, Dold G, Trang D, Simmons N, Perez A, Young NB, Barbaro RP, Piven J, Magnuson TR, Crawley JN (2004) Automated apparatus for quantitation of social approach behaviors in mice. Genes, brain, and behavior 3(5):303-314

Njung'e K, Handley SL (1991) Effects of 5-HT uptake inhibitors, agonists and antagonists on the burying of harmless objects by mice; a putative test for anxiolytic agents. British journal of pharmacology 104(1):105-112

Pearson BL, Defensor EB, Blanchard DC, Blanchard RJ (2010) C57BL/6J mice fail to exhibit preference for social novelty in the three-chamber apparatus. Behavioural brain research 213(2):189-194 
Peter Z, Oliphant ME, Fernandez TV (2017) Motor Stereotypies: A Pathophysiological Review. Frontiers in neuroscience 11171

Portfors CV, Perkel DJ (2014) The role of ultrasonic vocalizations in mouse communication. Current opinion in neurobiology 28115-120

Presti MF, Watson CJ, Kennedy RT, Yang M, Lewis MH (2004) Behavior-related alterations of striatal neurochemistry in a mouse model of stereotyped movement disorder. Pharmacology, biochemistry, and behavior 77(3):501-507

Raux G, Bumsel E, Hecketsweiler B, van Amelsvoort T, Zinkstok J, Manouvrier-Hanu S, Fantini C, Breviere GM, Di Rosa G, Pustorino G, Vogels A, Swillen A, Legallic S, Bou J, Opolczynski G, Drouin-Garraud V, Lemarchand M, Philip N, Gerard-Desplanches A, Carlier M, Philippe A, Nolen MC, Heron D, Sarda P, Lacombe D, Coizet C, Alembik Y, Layet V, Afenjar A, Hannequin D, Demily C, Petit M, Thibaut F, Frebourg T, Campion D (2007) Involvement of hyperprolinemia in cognitive and psychiatric features of the 22 11 deletion syndrome. Human molecular genetics 16(1):83-91

Richler J, Bishop SL, Kleinke JR, Lord C (2007) Restricted and repetitive behaviors in young children with autism spectrum disorders. Journal of autism and developmental disorders 37(1):73-85

Rizzo SJ (2016) Repetitive Behavioral Assessments for Compound Screening in Mouse Models of Autism Spectrum Disorders. Methods in molecular biology 1438293-310 Roubertoux P L, Carlier M, Tordjman S, (2015) Deficit in Social Relationships and Reduced Field of Interest in Mice. In: Roubertoux PL (ed) organism Models of Autism Spectrum Disorder, New York: Springer p. 335-70. 
Roubertoux PL (2015) Maintaining Mice for Neurobehavioral Examination. In: Roubertoux PL (ed) organism models of autism spectrum disorders. Springer, New York, pp 319333

Roubertoux PL, Baril N, Cau P, Scajola C, Ghata A, Bartoli C, Bourgeois P, Christofaro JD, Tordjman S, Carlier M (2017) Differential Brain, Cognitive and Motor Profiles Associated with Partial Trisomy. Modeling Down Syndrome in Mice. Behavior genetics $47(3): 305-322$

Roubertoux PL, Martin B, Le Roy I, Beau J, Marchaland C, Perez-Diaz F, Cohen-Salmon C, Carlier M (1996) Vocalizations in newborn mice: genetic analysis. Behavior genetics $26(4): 427-437$

Roubertoux PL, Tordjman S (2015) The autistic spectrum disorders (ASD): from the clinics to the molecular analysis. In: Roubertoux PL (ed) Organism models of Autism Spectrum Disorders. Springer, New York, pp 29-66

Scahill L, Dimitropoulos A, McDougle CJ, Aman MG, Feurer ID, McCracken JT, Tierney E, Pu J, White S, Lecavalier L, Hallett V, Bearss K, King B, Arnold LE, Vitiello B (2014) Children's Yale-Brown obsessive compulsive scale in autism spectrum disorder: component structure and correlates of symptom checklist. Journal of the American Academy of Child and Adolescent Psychiatry 53(1):97-107 e101

Shuster J, Perry A, Bebko J, Toplak ME (2014) Review of factor analytic studies examining symptoms of autism spectrum disorders. Journal of autism and developmental disorders 44(1):90-110

Silverman JL, Smith DG, Rizzo SJ, Karras MN, Turner SM, Tolu SS, Bryce DK, Smith DL, Fonseca K, Ring RH, Crawley JN (2012) Negative allosteric modulation of the 
mGluR5 receptor reduces repetitive behaviors and rescues social deficits in mouse models of autism. Science translational medicine 4(131):131ra151

Silverman JL, Yang M, Lord C, Crawley JN (2010) Behavioural phenotyping assays for mouse models of autism. Nature reviews Neuroscience 11(7):490-502

Smith CJ, Lang CM, Kryzak L, Reichenberg A, Hollander E, Silverman JM (2009) Familial associations of intense preoccupations, an empirical factor of the restricted, repetitive behaviors and interests domain of autism. Journal of child psychology and psychiatry, and allied disciplines 50(8):982-990

Sorensen EM, Bertelsen F, Weikop P, Skovborg MM, Banke T, Drasbek KR, Scheel-Kruger J (2015) Hyperactivity and lack of social discrimination in the adolescent Fmr1 knockout mouse. Behavioural pharmacology 26(8 Spec No):733-740

Szatmari P, Georgiades S, Bryson S, Zwaigenbaum L, Roberts W, Mahoney W, Goldberg J, Tuff $L$ (2006) Investigating the structure of the restricted, repetitive behaviours and interests domain of autism. Journal of child psychology and psychiatry, and allied disciplines 47(6):582-590

Tan A, Salgado M, Fahn S (1997) The characterization and outcome of stereotypical movements in nonautistic children. Movement disorders : official journal of the Movement Disorder Society 12(1):47-52

Thomas A, Burant A, Bui N, Graham D, Yuva-Paylor LA, Paylor R (2009) Marble burying reflects a repetitive and perseverative behavior more than novelty-induced anxiety. Psychopharmacology 204(2):361-373

Tobias S, Carlson JE (1969) Brief Report: Bartlett's Test of Sphericity and Chance Findings in Factor Analysis. Multivariate behavioral research 4(3):375-377 
Tordjman S, Cohen D, Anderson GM, Botbol M, Canitano R, Coulon N, Roubertoux PL (2018) Reframing autism as a behavioral syndrome and not a specific mental disorder: Implications of genetic and phenotypic heterogeneity. Neuroscience and biobehavioral reviews 89132-150

Tordjman S, Drapier D, Bonnot O, Graignic R, Fortes S, Cohen D, Millet B, Laurent C, Roubertoux PL (2007) Animal models relevant to schizophrenia and autism: validity and limitations. Behavior genetics 37(1):61-78

Tureck K, Matson JL, May A, Turygin N (2013) Externalizing and tantrum behaviours in children with ASD and ADHD compared to children with ADHD. Developmental neurorehabilitation 16(1):52-57

Turner-Brown LM, Lam KS, Holtzclaw TN, Dichter GS, Bodfish JW (2011) Phenomenology and measurement of circumscribed interests in autism spectrum disorders. Autism : the international journal of research and practice 15(4):437-456

Uljarevic M, Arnott B, Carrington SJ, Meins E, Fernyhough C, McConachie H, Le Couteur A, Leekam SR (2017) Development of restricted and repetitive behaviors from 15 to 77 months: Stability of two distinct subtypes? Developmental psychology 53(10):18591868

van Lang ND, Boomsma A, Sytema S, de Bildt AA, Kraijer DW, Ketelaars C, Minderaa RB (2006) Structural equation analysis of a hypothesised symptom model in the autism spectrum. Journal of child psychology and psychiatry, and allied disciplines 47(1):3744

Warrier V, Toro R, Chakrabarti B, i P-Bag, Borglum AD, Grove J, andMe Research T, Hinds DA, Bourgeron T, Baron-Cohen S (2018) Genome-wide analyses of self-reported 
empathy: correlations with autism, schizophrenia, and anorexia nervosa.

Translational psychiatry 8(1):35

Wasserstein RL, Nicole A. Lazar NA (2016) The ASA's Statement on p-Values: Context, Process, and Purpose. The American Statistician 70(2):129-133

Welch JM, Lu J, Rodriguiz RM, Trotta NC, Peca J, Ding JD, Feliciano C, Chen M, Adams JP, Luo J, Dudek SM, Weinberg RJ, Calakos N, Wetsel WC, Feng G (2007) Cortico-striatal synaptic defects and OCD-like behaviours in Sapap3-mutant mice. Nature 448(7156):894-900

Wolmarans W, Stein DJ, Harvey BH (2017) A psycho-behavioral perspective on modelling obsessive-compulsive disorder (OCD) in animals: The role of context. Current medicinal chemistry

Yadav R, Gupta SC, Hillman BG, Bhatt JM, Stairs DJ, Dravid SM (2012) Deletion of glutamate delta-1 receptor in mouse leads to aberrant emotional and social behaviors. PloS one $7(3): \mathrm{e} 32969$

Yang M, Crawley JN (2009) Simple behavioral assessment of mouse olfaction. Current protocols in neuroscience Chapter 8 Unit 824

Yu X, Taylor AMW, Nagai J, Golshani P, Evans CJ, Coppola G, Khakh BS (2018) Reducing Astrocyte Calcium Signaling In Vivo Alters Striatal Microcircuits and Causes Repetitive Behavior. Neuron 99(6):1170-1187 e1179

Zuo L, Tan Y, Zhang X, Wang X, Krystal J, Tabakoff B, Zhong C, Luo X (2015) A New Genomewide Association Meta-Analysis of Alcohol Dependence. Alcoholism, clinical and experimental research 39(8):1388-1395 
Figure captions

Figure 1: plan and measures of the two-chamber set up.

Figure 2: Cross validation of the variables used in the factor analysis in Tshz3 ${ }^{\text {Lacz+ }}$ and in wild-type mice. A) Distance walked in peripheral zone proportion; B) Zone crossing proportion; C) Distance in the central area proportion; D) Number of rearing; E) Burrowing activity; F) Number of leaning; G) Marble-burying score; H) Sociability; I) Interest in social novelty; J) Proportion of stereotyped dips; K) Self-grooming in the litter box; L) Number of self-grooming episodes; M) Exploration of new object; N) Number of jumping. See section RESULTS, sub-section Cross-validation for sample size and effect size of the differences. ${ }^{*} \mathrm{p} \leq 0.05 ;{ }^{* *} \mathrm{p} \leq 0.01 ; * * * \mathrm{p} \leq 0.001$ 
$550 \mathrm{~mm}$

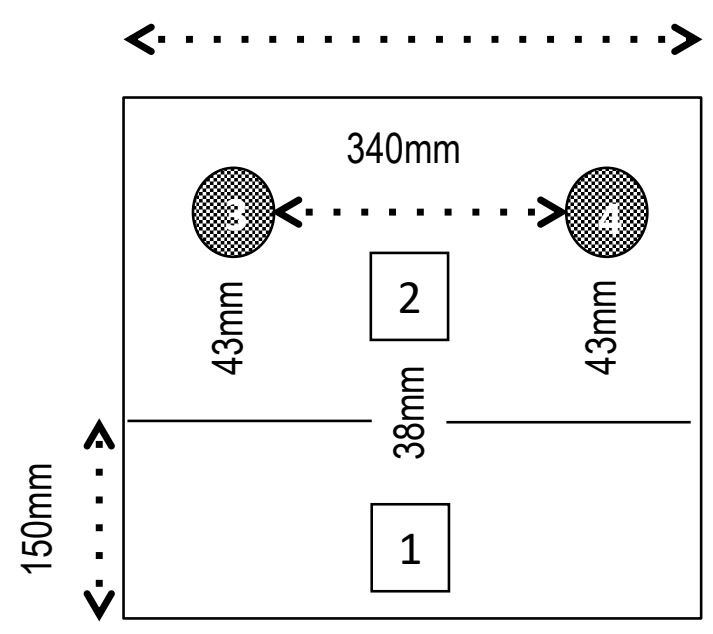



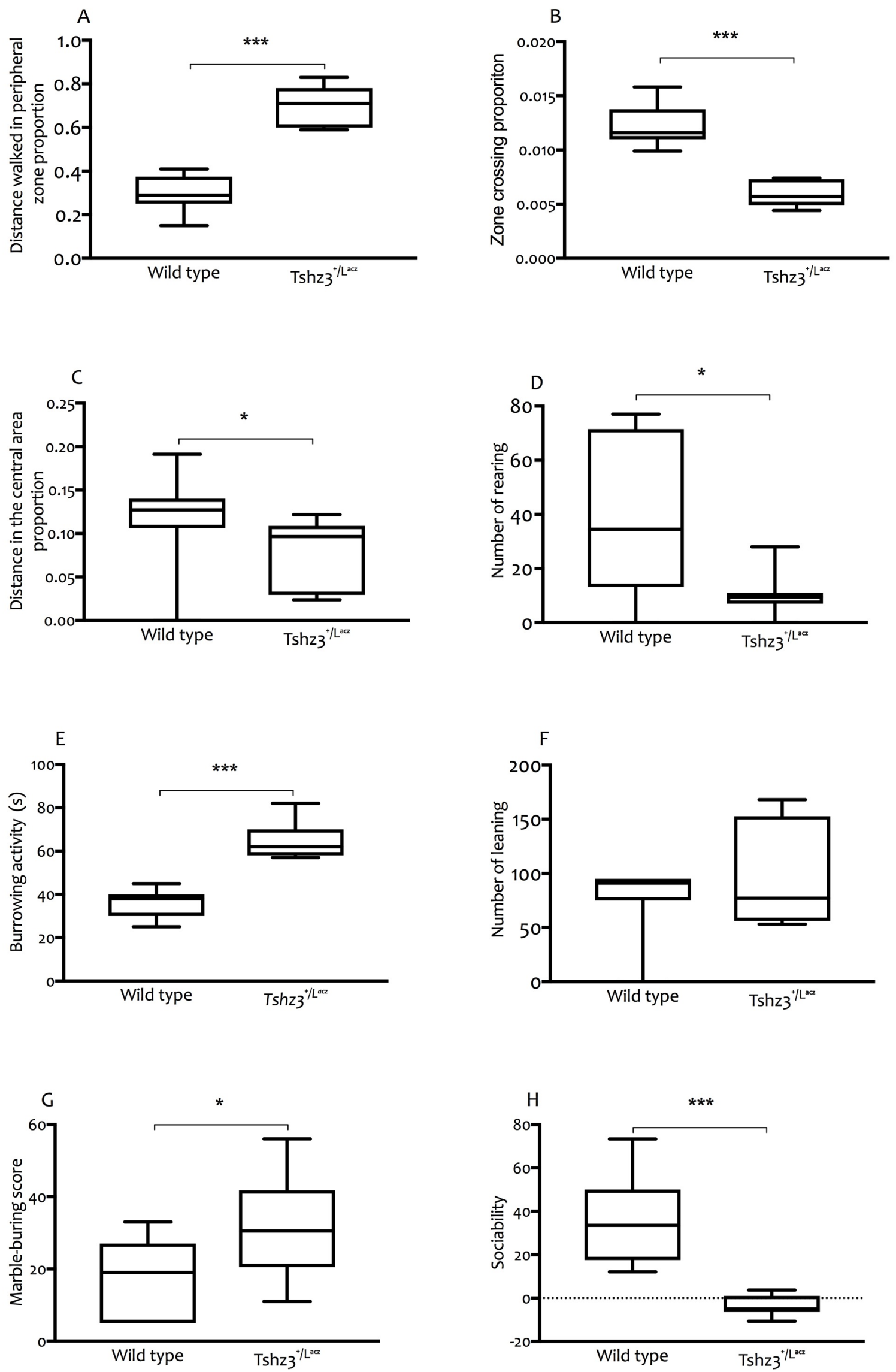

Fig. 2 

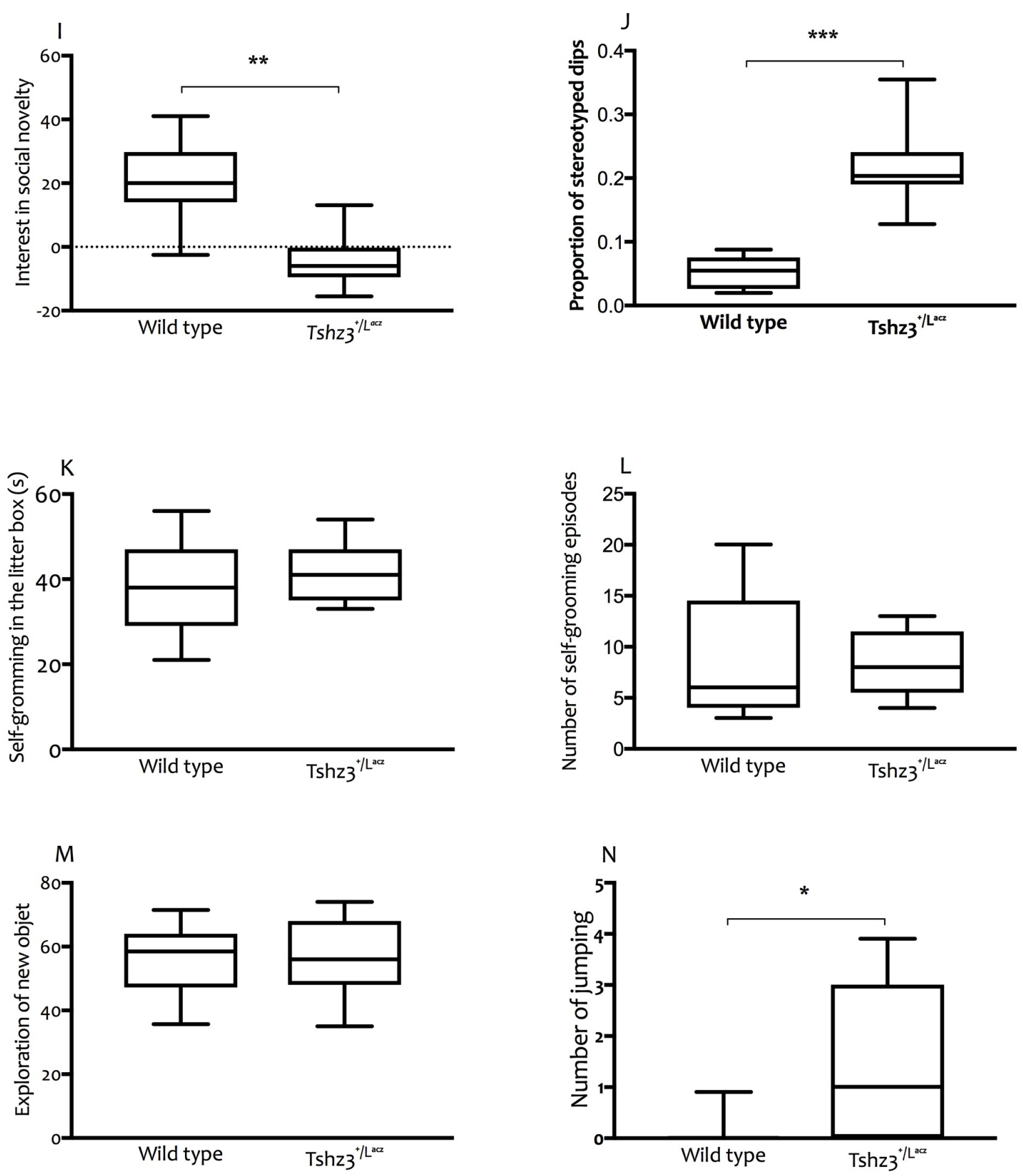

Fig. 2 continued 
Table 1: reliability of the measures of ASD-like features in mice.

Variable

Split half coefficient or

correlation

Distance walked in peripheral zone proportion Internal consistency

Zone crossing proportion

Internal consistency

0.75

Distance in the central area proportion

Internal consistency

0.78

Number of rearing

Internal consistency

0.82

Burrowing activity

Test retest

0.82

Number of jumping

Internal consistency

0.91

Number of leaning

Internal consistency

0.81

Marble-burying score

Test retest

0.89

Sociability

Internal consistency

Interest in social novelty

Internal consistency

0.92

Proportion of stereotyped dips

Test retest

0.77

Self-grooming in the litter box

Test retest

0.69

Number of self-grooming episodes

Internal consistency

0.68

Exploration of new object

Internal consistency

0.89 
Table 2: Correlation matrix of the measures modeling ASD core features in mice ${ }^{1}$

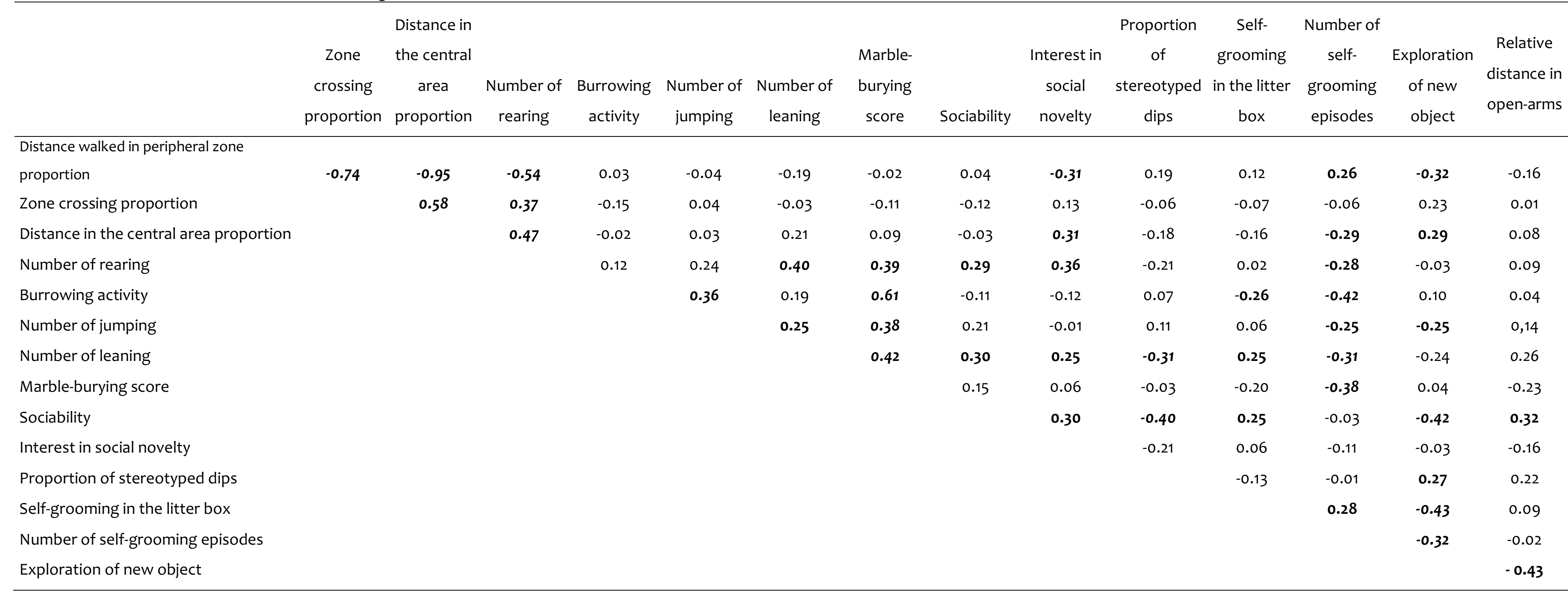

${ }^{1}$ The variable Relative distance in open-arms of the elevated-plus maze is not included in the factor analysis.

$\mathrm{N}$ varies between 63 and $65-$ see text. Bold $p \leq .05$; Bold and italic $p \leq .01$ 
Table 3: test of goodness of fit corresponding to the extraction of a) 2 factors in a partial analysis of stereotypy variables and b) 3,4 and 5 factors in a battery of tests measuring ASD-like features in mice.

\begin{tabular}{lccccc}
\hline & $\begin{array}{c}\text { Number } \\
\text { of factors }\end{array}$ & \% of variance & $K^{2}$ value & $\begin{array}{c}\text { Degree of } \\
\text { freedom }\end{array}$ & $p$ \\
\hline $\begin{array}{l}\text { a) Partial battery } \\
\text { (stereotypy) }\end{array}$ & 2 & 59 & 14.57 & 15 & 0.335 \\
$\begin{array}{l}\text { b) Whole battery } \\
\text { (S) }\end{array}$ & 3 & 60 & 81.088 & 52 & 0.006 \\
& 5 & 67 & 51.808 & 41 & 0.120 \\
& 74 & 34.414 & 31 & 0.308 \\
\hline
\end{tabular}

Table 4: Measures of stereotyped behavior in mouse models of ASD, varimax matrix.

\begin{tabular}{lcc}
\hline \multicolumn{1}{c}{ Measures } & Factor 1 & Factor 2 \\
\hline Number of rearing & $\mathbf{0 . 3 8}$ & $\mathbf{0 . 3 1}$ \\
Burrowing activity & $\mathbf{0 . 7 5}$ & -0.21 \\
Number of jumping & $\mathbf{0 . 4 6}$ & 0.06 \\
Number of leaning & $\mathbf{0 . 4 7}$ & $\mathbf{0 . 7 7}$ \\
Marble-burying score & $\mathbf{0 . 8 1}$ & 0.06 \\
Proportion of stereotyped dips & 0.00 & $\mathbf{0 . 3 9}$ \\
Self-grooming in the litter box & -0.26 & $\mathbf{0 . 4 6}$ \\
Number of self-grooming episodes & -0.55 & 0,04 \\
\hline
\end{tabular}

In bold, loadings $\geq 0.31(\mathrm{p} \leq 0.01)$. 
Table 5: Factor analysis of ASD-like measures in mice, Varimax matrix ( 5 iterations) after Kaiser normalization.

\section{Factors}

\begin{tabular}{|c|c|c|c|c|c|}
\hline Measures & 1 & 2 & 3 & 4 & 5 \\
\hline $\begin{array}{l}\text { Distance walked in peripheral zone } \\
\text { proportion }\end{array}$ & -0.96 & -0.04 & -0.19 & -0.18 & 0.09 \\
\hline Zone crossing proportion & 0.79 & -0.07 & -0.01 & 0.02 & 0.17 \\
\hline Distance in the central area proportion & 0.87 & 0.06 & 0.21 & 0.21 & -0.39 \\
\hline Number of rearing & 0.45 & 0.35 & 0.53 & 0.03 & 0.15 \\
\hline Burrowing activity & -0.04 & 0.79 & -0.19 & 0.12 & 0.04 \\
\hline Number of jumping & 0.06 & 0.53 & 0.07 & -0.23 & 0.03 \\
\hline Number of leaning & 0.08 & 0.41 & 0.52 & -0.09 & -0.05 \\
\hline Marble-burying score & -0.11 & 0.79 & 0.21 & 0.21 & -0.11 \\
\hline Sociability & -0.13 & 0.09 & 0.64 & -0.23 & 0.02 \\
\hline Interest in social novelty & 0.21 & -0.04 & 0.51 & 0.07 & -0.03 \\
\hline Proportion of stereotyped dips & -0.14 & 0.02 & -0.45 & 0.19 & 0.03 \\
\hline Self-grooming in the litter box & -0.08 & -0.19 & 0.28 & -0.39 & 0.14 \\
\hline Number of self-grooming episodes & -0.15 & -0.46 & -0.11 & -0.39 & 0.08 \\
\hline Exploration of new object & 0.22 & -0.07 & -0.27 & 0.93 & 0.09 \\
\hline
\end{tabular}

In Bold, loadings $\geq .31(\mathrm{p} \leq .01)$ 